\title{
Comparative Molecular Field Analysis (CoMFA) and Comparative Molecular Similarity Index Analysis (CoMSIA) Study of Mutagen X
}

\author{
Soo Jin Bang and Seung Joo Cho* \\ Life Science Division, Korea Instihte of Science and Technology, Seoul 130-650. Korea \\ Received.huly 22, 2004
}

\begin{abstract}
Mutagen X (MX) exists in our drinking water as the bi-products of chlorine disinfection. Being one of the most potent mutagen, it attracted much attention from many researchers. $\mathrm{MX}$ and its analogs are synthesized and modeled by quantitative structure activity relationship (QSAR) methods. As a result, factors affecting this class of compounds have been found to be steric and electrostatic effects. We tried to collect all the data available from the literature. With both COMFA and COMSIA various combinations of physiochemical parameters were systematically studied to produce reasonable 3-dimensional models. The best model for CoMFA gave $q^{2}=0.90$ and $r^{2}=0.97$, while for CoMSlA $q^{2}=0.85$ and $r^{2}=0.94$. So the models seem to be reasonable. Unlike previous result of COMFA, in our case steric parameter alone gave the best statistics. Although the steric contribution was found to be the most important in both COMFA and CoMSIA, steric parameter along with electrostatic parameter produced slightly better model in CoMSIA. Overall, steric contribution is clearly the most important single factor. However, when we compare chlorine and bromine substitution, chlorine substitution can be more mutagenic. This indicates that other factors such as electrostatic effect also influence the mutagenicity. From the contour maps, steric contribution seems to be focused on rather small area near $\mathrm{C} 6$ substituent of the furanone ring, rather than $\mathrm{C} 3$ substituent. Therefore the locality of steric contribution can play a significant role in mutagenicity.
\end{abstract}

Key Words : Mutagen X. Mutagenicity, CoMFA. CoMSIA, QSAR

\section{Introduction}

Chlorine bleaching disinfects our drinking water by reducing the water-mediated diseases. However, some of the bi-products caused by this disinfection process are highly mutagenic.' Although how MX (3-chloro-4-(dichloromethyl)-5-hydroxyl-2(5H)-furanone) is produced in water is not clearly understood. ${ }^{2} \mathrm{MX}$ is a potent mutagen ever tested in Ames test with test strain TA100." The mutagenicity of $\mathrm{MX}$ has been reported $3430-13800$ induced reversants per nanomole in the Ames assay without $\mathrm{S} 9$ mix. This unusual high mutagenicity attracted considerable attention from many researchers. ${ }^{+}$Until recently, $\mathrm{MX}$ was assumed to pose little carcinogenic risk due to its low exposure, high reactivity and short residence time. ${ }^{5}$ But recent identification of DNA adducts ${ }^{6}$ and evidence of carcinogenicity along the gastro-intestinal lining in rodents following $\mathrm{MX}$ exposure has heightened concern for this class of chemicals. MX can alter the metabolic pathway when it is administered in rats in high dosage. ${ }^{7}$ It is also found to induce apoptosis of HL-60 cells. ${ }^{8} \mathrm{~A}$ relatively large number of $\mathrm{MX}$ analogs have been synthesized." tested for mutagenicity." subject to many experimental studies. As a result, the resultant $\mathrm{MX}$ analogs show wide range of mutagenicity. "They are modeled by structure-activity relationship methods. ${ }^{12}$ In spite of this multitude of studies, basic questions concerning the nature of the reactive species and the mechanism of interaction of

To whom correspondence should be addressed. e-mail: chosja: kist.re.kr these compounds with DNA to produce their remarkable mutagenic potency in SAL [A 100 remain unresolved.

MX exists as an equilibrium mixture of both ring and open form in water as shown in Higure 1 . The relative concentration of ring and open form depends heavily on the $\mathrm{pH}$ of the solution. If the aqueous solution is highly acidic, the ring form is dominant species. At pH 5.5 the ratio of ring form and open form is $1: 1$. The relative concentration of open form becomes high as the solution gets more basic. This is a fast equilibrium process. ${ }^{1.7}$ To study factors affecting the mutagenicity, there have been a few quantitative structure activity relationship (QSAR) studies. The structural and electronic properties were calculated using the semi-empirical AMI (Austin Model 1) method. The lowest unoccupied frontier orbital (LUMO) was found to be important by using

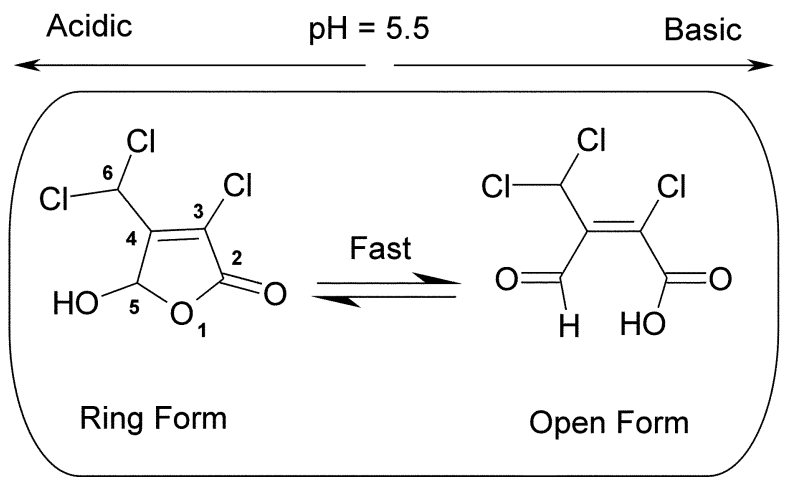

Figure 1. Two lorms of $\mathrm{MX}$ in equilibrium. 


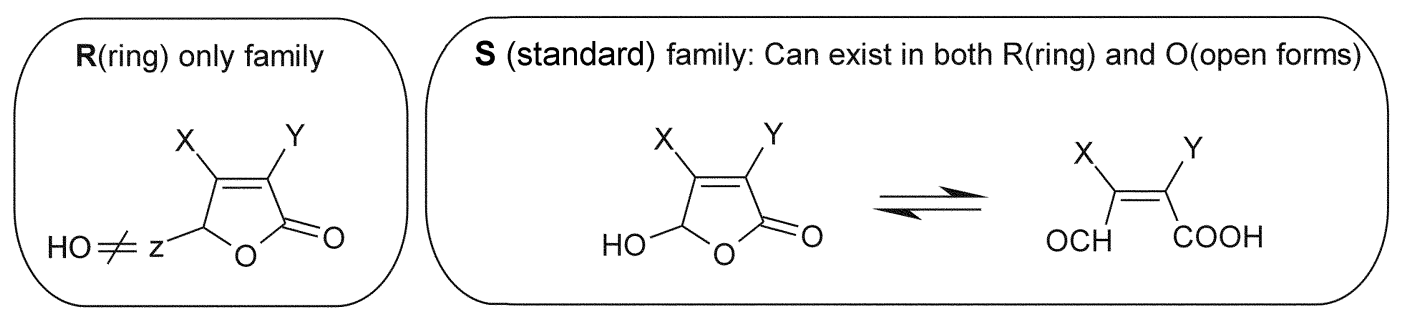

Figure 2. Two families of $\mathrm{MX}$ analogs.

this quantum mechanical method. ${ }^{\text {2hoc }}$ This may imply that $\mathrm{MX}$ acts as an electron acceptor. In particular, I.UMO electron density and partial charge of the C3 correlated with mutagenicity, Flectron density near $\mathrm{C} 3$ also showed negative

Table 1. The Mutagenicity of MX analogs

\begin{tabular}{|c|c|c|c|c|c|}
\hline & $X$ & $\mathrm{Y}$ & $Z$ & $\ln (T \wedge 100)$ & V \\
\hline \multicolumn{6}{|c|}{ Standard Family } \\
\hline $\mathrm{S} 1(\mathbf{M X})$ & $\mathrm{CHCl}_{2}$ & $\mathrm{Cl}$ & & 8.62 & 9 \\
\hline S2 (B.MX2) & $\mathrm{CHBr}_{2}$ & $\mathrm{Cl}$ & & 8.61 & I \\
\hline S3 (B.MX3) & $\mathrm{CHBr}_{2}$ & $\mathrm{Br}$ & & 6.41 & $2^{*}$ \\
\hline S4 (CMCF) & $\mathrm{CH}_{2} \mathrm{Cl}$ & $\mathrm{Cl}$ & & 6.37 & 5 \\
\hline S5 (BMBF) & $\mathrm{CH}_{2} \mathrm{Br}$ & $\mathrm{Br}$ & & 6.04 & 1 \\
\hline $\mathrm{S} 6(\mathrm{MCA})$ & $\mathrm{Cl}$ & $\mathrm{Cl}$ & & 1.87 & $6^{2 t}$ \\
\hline S7 (MBA) & $\mathrm{Br}$ & $\mathrm{Br}$ & & 1.71 & I \\
\hline $\mathbf{S 8}$ & $\mathrm{CH}_{2} \mathrm{Cl}$ & $\mathrm{H}$ & & 1.35 & 3 \\
\hline $\mathrm{S} 9$ (MBF) & $\mathrm{CH}_{3}$ & $\mathrm{Br}$ & & 0.41 & 1 \\
\hline S10 (MCF) & $\mathrm{CH}_{3}$ & $\mathrm{Cl}$ & & 0.21 & 4 \\
\hline S11 & $\mathrm{H}$ & $\mathrm{Cl}$ & & -1.61 & 1 \\
\hline $\mathrm{S} 12$ (MF) & $\mathrm{CH}_{3}$ & $\mathrm{H}$ & & -3.51 & 2 \\
\hline \multicolumn{6}{|l|}{ Ring Fanily } \\
\hline RI & $\mathrm{CHBr}_{2}$ & $\mathrm{Cl}$ & $\mathrm{OCH}_{3}$ & 8.65 & I \\
\hline $\mathbf{R} 2$ & $\mathrm{CHCl}_{2}$ & $\mathrm{Cl}$ & $\mathrm{OCH}_{3}$ & 8.65 & I \\
\hline $\mathbf{R 3}$ & $\mathrm{CHBr}_{2}$ & $\mathrm{Cl}$ & $\mathrm{H}$ & 5.20 & I \\
\hline R4 & $\mathrm{CHBr}_{2}$ & $\mathrm{Br}$ & $\mathrm{H}$ & 4.86 & 1 \\
\hline R5 (RMX) & $\mathrm{CHCl}_{2}$ & $\mathrm{Cl}$ & $\mathrm{H}$ & 4.54 & 6 \\
\hline R6 & $\mathrm{CH}_{2} \mathrm{Br}$ & $\mathrm{Br}$ & $\mathrm{H}$ & 2.11 & 1 \\
\hline $\mathbf{R} 7$ & $\mathrm{CH}_{2} \mathrm{Cl}$ & $\mathrm{Cl}$ & $\mathrm{H}$ & 1.70 & 4 \\
\hline $\mathbf{R 8}$ & $\mathrm{CH}_{2} \mathrm{Cl}$ & $\mathrm{Br}$ & $\mathrm{H}$ & 1.37 & 1 \\
\hline R9 & $\mathrm{CH}_{2} \mathrm{Br}$ & $\mathrm{Cl}$ & $\mathrm{H}$ & 1.37 & 1 \\
\hline $\mathbf{R} 10$ & $\mathrm{Cl}$ & $\mathrm{Cl}$ & $\mathrm{OCH}_{3}$ & 0.99 & I \\
\hline R11 & $\mathrm{CH}_{3}$ & $\mathrm{Cl}$ & $O C_{2} \mathrm{H}_{5}$ & 0.74 & I \\
\hline R12 & $\mathrm{Br}$ & $\mathrm{Br}$ & $\mathrm{H}$ & 0.17 & I \\
\hline R13 & $\mathrm{H}$ & $\mathrm{Cl}$ & $O C_{2} \mathrm{H}_{5}$ & -0.22 & I \\
\hline R14 & $\mathrm{CH}_{3}$ & $\mathrm{Cl}$ & $\mathrm{H}$ & -0.78 & $2^{h}$ \\
\hline R15 & $\mathrm{Cl}$ & $\mathrm{Cl}$ & $\mathrm{H}$ & -0.62 & 2 \\
\hline R16 & $\mathrm{CH}_{2} \mathrm{Cl}$ & $\mathrm{H}$ & $\mathrm{H}$ & -1.59 & $3^{4 t}$ \\
\hline R17 & $\mathrm{CHCl}_{2}$ & $\mathrm{H}$ & $\mathrm{H}$ & -2.41 & $2^{h}$ \\
\hline
\end{tabular}

Dala in this table comprise of 15 reports. $N$ is the number of repots that have mutagenicity data. $\mathrm{X}, \mathrm{Y}$ and $\%$ are substituents for $\mathrm{MX}$ analogs as shown in Figure $2 . \ln (\mathrm{TA} 100)$ is the natural log for experimental values (revinm in $A$ mes test). When there atre mure than two repurts, illter the logatillmos have been taken, the values are averaged. and the resultant values are listed in this table. "Ihe maximum value is more than one order larger than the minimum value in magnitude. "One of the reports indicales that the compound is not mutagenic and logarithns are taken for temaining value. linear dependency by NMR study. Comparative molecular field analysis (COMFA) indicated that the steric properties of MX analogs with their electron-accepting ability explain their mutagenic activity almost completely. ${ }^{1.1}$ However, these studies are based on a few reports and some of the structurally relevant compounds were never considered for QSAR studies. In this study, we tried to include all the data available from the literature and summarized in Table 1. At a glance, as the degree of halogen substitution increases, the mutagenicity also increases.

The compounds are collected from the available reports and categorized into two groups as shown in Figure 2. Compounds which belongs to standard family (S) contain the structure of 5 -hydroxy- $2(5 \mathrm{H})$-furanone. These compounds are capable of conversion between hydroxyl ring form and aldehyde open form like MX. If an analog has a ring form and does not have 5-hydroxyl group, then it cannot be converted into the corresponding open form. Therefore it belongs to ring family $(\mathbf{R})$. The mutagenicity of $\mathrm{MX}$ is the average value of 9 different studies. "I All the activity values are within the order of magnitude (3430-13800). Thus the average value can be considered highly reliable. The whole set comprises of 29 compounds. The range of activity is fairly well spread for any particular family as well as for the whole set. All the compounds have $\alpha \beta$-unsaturated acidic moiety as a common structure. This structural resemblance might imply that these compounds induce mutagenicity with the same mechanisın.

\section{Methods}

Quantitative structure-activity relationships (QSARs) are important tools to understand why the active compounds exhibit certain biochemical activities. ${ }^{1.5}$ The challenge is to improve the accuracy and predictability of QSAR model by taking into account the structural and physicochemical features of the concerned compounds. One of the most widely used tools in $3 \mathrm{D}$ QSAR study is comparative molecular field analysis (COMFA). ${ }^{15}$ CoMFA is based on the assumption that changes in the biological activity correlate with changes in the steric and electrostatic fields of molecules. CoMFA calculates steric fields using a LennardJones potential, and electrostatic fields using a Coulombic potential. While this approach has been widely accepted and scientifically feasible, it is not without problems. Both potential functions are very steep near the van der Waals surface of the molecule, causing rapid changes, and 
requiring the use of cut-off values. So changes in orientation of the superimposed molecules, relative to the calculation grid, can cause significant changes in CoMFA results. In addition, a scaling factor is applied to the steric field, so both fields can be used in the same PIS analysis. In CoMSIA (Comparative Molecular Similarity Index Analysis), a recently developed technique, ${ }^{16}$ five different fields are calculated; steric, electrostatic, hydrophobic, hydrogen bond donor and hydrogen bond acceptor. These fields were selected to cover the major contributions to ligand binding. Similarity indices are calculated at regularly spaced grid points for the pre-aligned molecules. Using Gaussian type of function, CoMSIA is less sensitive on the grid spacing and its relative orientation of the aligned molecules and grid. These two methods have often been used together as complementary methods. The CoMFA and CoMSIA analyses were performed on a Silicon Graphics workstation (IRIX 6.5 operating system) with SYBYl, 6.9.2. The steric and electrostatic CoMFA descriptors were calculated with the standard Tripos forcefield at every point of the three dimensional lattice, using the $\mathrm{sp}^{3}$ carbon probe with +1 charge with standard CoMFA cutoff values. For standard fannily, we do not know either ring form or open form is responsible for the mutagenicity. In this work, since ring fatmily can exist only in ring form, ring form was used for standard family for these $3 \mathrm{D}$ QSAR techniques. This ensures the consistency and maximum overlap between two families. The three-dimensional molecular structures of the compounds in the data sets were fully optimized and atomic charges were calculated with AM1 (Austin Model 1) Hamiltonian. The resultant charges were used for electrostatic parameter calculations. All the possible conformations were generated and selected based on the minimum energy. The energy levels of L.LMO were derived from these conformations. ${ }^{17}$ Then the chosen conformers were superimposed as shown in Figure 3 by matching corresponding atoms in the 5 membered ring. CoMFA standard scaling was applied whenever scaling was necessary between different parameters. CoMFA standard scaling often gives results better than those obtained using uniform weighting. ${ }^{\text {I }}$

\section{Results}

As shown in lable 2, we have tried 5 grid spacings for CoMFA. It started with the default $2.0 \AA$ grid spacing, then we increased the model resolution up to $0.1 \bar{\AA}$. If the grid spacing is large e.g., the default of $2 \AA$, the results can be sensitive to the alignments with respect to the grid. Reduction of the grid spacing would reduce this sensitivity. Also with more grid points, a better model could be expected. As expected, there is a tendency that high resolution of grid spacing would give higher $\mathrm{q}^{2}$ and $\mathrm{r}^{2}$. When we compare the grid spacings of $0.1 \AA$ and $0.2 \AA$, both results are almost the same, indicating saturation of grid points. If we consider single parameter, steric factor $(\mathbf{S})$ gave highest predictive power as well as explanatory one over any other parameters ( $\left.\mathbf{E}, \mathbf{E}_{\mathrm{LI} \text { no }}\right)$. Combination of these param-

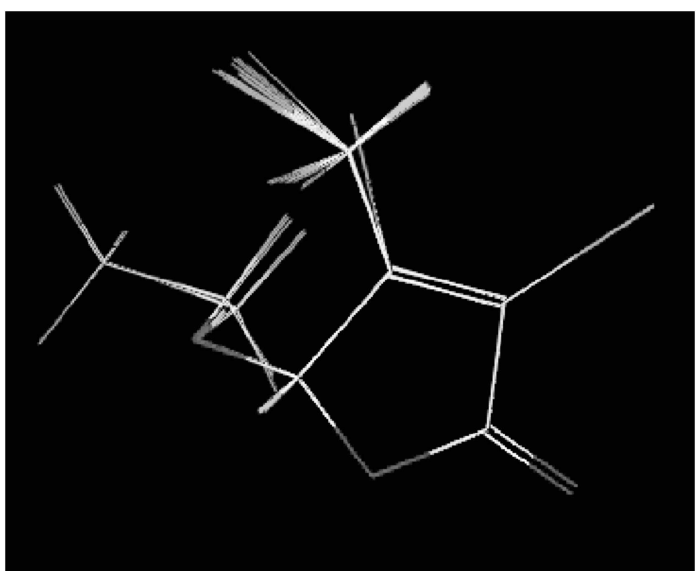

Figure 3. Superposition of MX analogs used in CoMFA and CoMSIA sludies.

eters did not really improve the statistical parameters except for $\mathrm{S}, \Gamma_{\mathrm{LLANO}}$ at $1.0 \AA$. The best model was chosen based on the predictive power $\left(q^{2}\right)$. If $q^{2}$ values are equal, then explanatory power $\left(r^{2}\right)$ were considered. Thus the best model was obtained when steric factor alone was used at grid spacing $0.2 \AA$. Witl CoMSlA, we considered 5 parameters, so there are 31 possible combinations of parameters. These are listed in Table 3 . As in the cases of CoMFA, steric parameter seems to be most important when we consider single parameter. Combining two or more parameters did not really much improve statistical values. There are 4 cases those gave $\mathrm{q}^{2}$ values more than 0.7. Steric parameter is involved in all four cases as shown in Table 3 . The effect of grid spacing is also considered and listed in Table 4. Varying the model resolution did not change the statistical values much. The best model was obtained with steric parameter along with electrostatic parameter was $\mathrm{q}^{2}=0.80$ and $\mathrm{r}^{2}=$ 0.92. In Table 5, the predicted values for the compounds along with residuals are listed using the best CoMFA and CoMSIA models. For CoMrA the absolute values of residual for $\mathrm{Rl} 7$ and $\mathrm{Rl} 4$ were greater than the double of standard error $(0.703)$. So, these two molecules can be outliers for this model with more than $95 \%$ of confidence. There are contradictory reports for these two values. While in one report the mutagenicity of R17 is $0.09 \mathrm{rev} / \mathrm{nmol}$, in the other it is not mutagenic. Likewise, Rl4 also have two different values; one is $0.46 \mathrm{rev} / \mathrm{nm}$ l, the other not mutagenic. The mutagenicity of RI7 and RI4 in lable 5 is listed based on one report that they are mutagenic. There are chances that these values are incorrect. Therefore we performed CoMFA excluding these two potential outliers. The resultant CoMrA with the steric parameter gave $\mathrm{q}^{2}=$ 0.897 and $r^{2}=0.968$. For CoMSIA only $\mathrm{R} 17$ has the highest absolute residual value and was greater than double of standard error $(0.982)$. Therefore $\mathrm{R} 17$ was excluded in the CoMSIA model. The resultant CoMSIA with the steric and electrostatic parameters gave $q^{2}=0.854$ and $r^{2}=0.939$. Using these final models for CoMFA and CoMSIA, contour plots are drawn in Figure 4. A is the steric field map of 
Table 2. Grid Spacing Variation and Statistical Paraneters (CoMFA)

\begin{tabular}{|c|c|c|c|c|c|c|}
\hline & $S$ & $\mathrm{E}$ & $E_{\text {LCMo }}$ & $\mathrm{S}, \mathrm{E}$ & $\mathrm{S}, \mathrm{E}_{\text {LUIMOI }}$ & $\mathrm{S}, \mathrm{E}, \mathrm{E}_{\mathrm{LCMM}}$ \\
\hline \multicolumn{7}{|l|}{$\overline{2.0 . \dot{4}}$} \\
\hline $\mathrm{q}^{\hat{2}}$ & 0.822 & 0.769 & 0.702 & 0.782 & 0.811 & 0.782 \\
\hline number of comp. & 8 & 5 & 1 & 5 & 5 & 5 \\
\hline$r^{2}$ & 0.951 & 0.900 & 0.743 & 0.919 & 0.914 & 0.930 \\
\hline $\mathrm{F}$ & 48.331 & 41.605 & 78.106 & 51.917 & 48.994 & 61.530 \\
\hline \multicolumn{7}{|l|}{ contribution natio } \\
\hline Steric & 1.000 & & & 0.450 & 0.559 & 0.298 \\
\hline Electrostatic & & 1.000 & & 0.550 & & 0.295 \\
\hline $\mathrm{E}_{\text {LUMD }}$ & & & 1.000 & & 0.441 & 0.407 \\
\hline \multicolumn{7}{|l|}{$1.0 . \mathrm{A}$} \\
\hline$q^{2}$ & 0.836 & 0.803 & 0.702 & 0.820 & 0.843 & 0.825 \\
\hline number of comp. & 6 & 7 & 1 & 5 & 7 & 6 \\
\hline$T^{2}$ & 0.954 & 0.954 & 0.743 & 0.934 & 0.956 & 0.948 \\
\hline $\mathrm{F}$ & 75.610 & 61.646 & 78.106 & 64831 & 64.980 & 66.258 \\
\hline \multicolumn{7}{|l|}{ contribution ratio } \\
\hline Steric & 1.000 & & & 0.563 & 0.747 & 0.421 \\
\hline Electrostatic & & 1.000 & & 0.437 & & 0.307 \\
\hline$E_{\text {LIMYO }}$ & & & 1.000 & & 0.253 & 0.281 \\
\hline \multicolumn{7}{|l|}{0.5 .4} \\
\hline$q^{2}$ & 0.848 & 0.762 & $0.7(1) 2$ & 0.841 & 0.848 & 0.841 \\
\hline number of comp. & 7 & 6 & 1 & 7 & 7 & 7 \\
\hline$T^{2}$ & 0.946 & 0.894 & 0.743 & 0.945 & 0.933 & 0.939 \\
\hline $\mathrm{F}$ & 52.880 & 31.017 & 78.106 & 51.102 & 41.858 & 46.105 \\
\hline \multicolumn{7}{|l|}{ contribution rufio } \\
\hline Steric & 1.000 & & & 0.503 & 0.633 & 0.360 \\
\hline Electrostatic & & 1.000 & & 0.497 & & 0.291 \\
\hline ELIMO & & & 1.000 & & 0.367 & 0.350 \\
\hline \multicolumn{7}{|l|}{0.2 .4} \\
\hline $\mathrm{q}^{2}$ & 0.848 & 0.792 & 0.702 & 0.828 & 0.843 & 0.828 \\
\hline number of comp. & 5 & 4 & 1 & 4 & 5 & 4 \\
\hline$r^{2}$ & 0.951 & 0.912 & 0.743 & 0.930 & 0.949 & 0.931 \\
\hline $\mathrm{F}$ & 90.040 & 62.255 & 78.106 & 79.993 & 85.522 & 80.689 \\
\hline \multicolumn{7}{|l|}{ contribution rutio } \\
\hline Steric & 1.000 & & & 0.437 & 0.730 & 0.279 \\
\hline Electrostatic & & 1.000 & & 0.563 & & 0.403 \\
\hline$E_{\text {LUM: }}$ & & & 1.000 & & 0.270 & 0.318 \\
\hline \multicolumn{7}{|l|}{0.1 .4} \\
\hline$q^{2}$ & 0.847 & 0.792 & 0.702 & 0.832 & 0.847 & 0.832 \\
\hline number of comp. & 5 & 4 & 1 & 5 & 5 & 5 \\
\hline$r^{3}$ & 0.951 & 0.912 & 0.743 & 0.941 & 0.949 & 0.945 \\
\hline $\mathrm{F}$ & 90.040 & 62.255 & 78.106 & 73.166 & 85.522 & 78.996 \\
\hline \multicolumn{7}{|l|}{ contribution natio } \\
\hline Steric & 1.000 & & & 0.432 & 0.730 & 0.273 \\
\hline Electrostatic & & 1.000 & & 0.568 & & 0.447 \\
\hline$E_{\text {LUM: }}$ & & & 1.000 & & 0.270 & 0.280 \\
\hline
\end{tabular}

$q^{2}$ : leave-one-out crossvalidation. F: F ratio. ELuno: energy level of LUMO

CoMFA with steric parameter alone while D is that of CoMSIA. The green polyhedra indicate sterically favorable contribution while yellow areas are disfavored. The favorable regions are located near $\mathrm{C} 3$ and $\mathrm{C} 6$ substituents. When both electrostatic and steric contribution were considered for model derivation. the steric contribution near C3 substituent disappears. only favoring C6 position (B. E). This indicates that the area near $\mathrm{C} 6$ is sterically more favored than that near C3 position. In electrostatic interaction field maps $(\mathbf{C}$. F), the blue polyhedra indicate the regions where positive charge endances the mutagenicity while red ones indicate that negative charge does. The electrostatic contour maps indi- 
Table 3. CoMSIA and various combination of paranneters

\begin{tabular}{|c|c|c|c|}
\hline & $\mathrm{q}^{2}$ & $\hat{1}$ & number of comp \\
\hline $\mathbf{S}$ & 0.762 & 0.869 & 5 \\
\hline $\mathbf{E}$ & 0.629 & 0.949 & 7 \\
\hline $\mathbf{H}$ & 0.648 & 0.798 & 4 \\
\hline D & 0.163 & 0.325 & 3 \\
\hline A & -0.081 & 0.192 & 3 \\
\hline$S \& E$ & 0.794 & 0.921 & 5 \\
\hline$D \& A$ & 0.260 & 0.588 & 4 \\
\hline $\mathbf{S}, \mathbf{E}$ & 0.371 & 0.752 & 4 \\
\hline $\mathbf{S}, \mathbf{H}$ & 0.728 & 0.880 & 6 \\
\hline S, D & 0.227 & 0.673 & 6 \\
\hline $\mathrm{S}, \mathrm{A}$ & 0.764 & 0.879 & 6 \\
\hline E, H & 0.612 & 0.920 & 7 \\
\hline E, D & -0.093 & 0.148 & 1 \\
\hline $\mathbf{E}, \mathbf{A}$ & 0.410 & 0.838 & 6 \\
\hline H, D & 0.153 & 0.418 & 2 \\
\hline $\mathbf{H}_{4} \mathbf{A}$ & 0.604 & 0.805 & 3 \\
\hline $\mathrm{D}, \mathrm{A}$ & 0.278 & 0.631 & 5 \\
\hline $\mathbf{S}, \mathbf{E}, \mathbf{H}$ & 0.621 & 0.917 & 6 \\
\hline S, E, D & 0.034 & 0.332 & 3 \\
\hline $\mathbf{S}, \mathbf{E}, \mathbf{A}$ & 0.331 & 0.662 & 3 \\
\hline S, H, D & 0.540 & 0.838 & 4 \\
\hline $\mathbf{S}, \mathbf{H}, \mathbf{A}$ & 0.576 & 0.773 & 3 \\
\hline S, D, A & 0.169 & 0.798 & 7 \\
\hline E, H, D & -0.167 & 0.163 & 1 \\
\hline $\mathbf{E}, \mathbf{H}, \mathbf{A}$ & 0.571 & 0.921 & 5 \\
\hline $\mathbf{E}, \mathbf{D}, \mathbf{A}$ & 0.017 & 0.485 & 7 \\
\hline H, D, A & 0.126 & 0.435 & 2 \\
\hline $\mathbf{S}, \mathbf{E}, \mathbf{H}, \mathbf{D}$ & -0.182 & 0.274 & 2 \\
\hline $\mathbf{S}, \mathbf{E}, \mathbf{H}, \mathbf{A}$ & 0.581 & 0.919 & 6 \\
\hline $\mathbf{S}, \mathbf{E}, \mathbf{D}, \mathbf{A}$ & 0.043 & 0.471 & 4 \\
\hline $\mathbf{S}, \mathbf{H}, \mathbf{D}, \mathbf{A}$ & 0.534 & 0.852 & 5 \\
\hline $\mathbf{E}, \mathbf{H}, \mathbf{D}, \mathbf{A}$ & -0.193 & 0.154 & 1 \\
\hline $\mathbf{S}, \mathbf{E}, \mathbf{H}, \mathbf{D}, \mathbf{A}$ & -0.144 & 0.115 & 1 \\
\hline
\end{tabular}

hydrogen bond acceptor

cated that we need some negative charge near the $\mathrm{C} 3$ position probably indicating electronegative substituents.

\section{Conclusion}

Although electrostatic contribution may slightly improve the statistics. CoMFA and CoMSIA gave consistent result that steric contribution is the most important. When we carefully look into the data in Table 1, there are cases that chlorine substitution enhances mutagenicity than sterically more bulky bromine substitution. i.e., S4 vs. S5. etc. Therefore. there could be some other minor effects such as electrostatic effect. The sterically important regions are somewhat localized on the area near C6 rather than $\mathrm{C} 3$ position. indicating $\mathrm{C} 6$ substitution might change mutagenicity more drantatically than $\mathrm{C} 3$. This is consistent with the conclusion of LaLonde et a. ${ }^{1 \text { le }}$ that the halogen-byhydrogen replacement at $\mathrm{C} 6$ induces the greatest nutagenicity reduction.
Table 4. Grid Spacing Variation (COMSIA)

\begin{tabular}{lrrrr}
\hline & $\mathrm{S}$ & $\mathrm{S}, \mathrm{E}$ & $\mathrm{S}, \mathrm{H}$ & $\mathrm{S}, \mathrm{A}$ \\
\hline $2.0 . A$ & & & & \\
$\mathrm{q}^{2}$ & 0.762 & 0.794 & 0.728 & 0.764 \\
$\mathrm{r}^{2}$ & 0.869 & 0.921 & 0.880 & 0.879 \\
number of comp. & 5 & 5 & 6 & 6 \\
\hline $\boldsymbol{l . 0 .}$ & & & & \\
$\mathrm{q}^{2}$ & 0.757 & 0.800 & 0.649 & 0.751 \\
$\mathrm{r}^{2}$ & 0.871 & 0.922 & 0.852 & 0.896 \\
number of comp. & 5 & 6 & 5 & 7 \\
\hline $0.5 A$ & & & & \\
$\mathrm{q}^{2}$ & 0.761 & 0.798 & 0.705 & 0.777 \\
$\mathrm{r}^{2}$ & 0.869 & 0.919 & 0.870 & 0.891 \\
number of comp. & 5 & 5 & 6 & 7 \\
\hline$a .2 . A$ & & & & \\
$\mathrm{q}^{2}$ & 0.761 & 0.790 & 0.705 & 0.777 \\
$\mathrm{r}^{2}$ & 0.869 & 0.919 & 0.870 & 0.891 \\
number of comp. & 5 & 5 & 6 & 7 \\
\hline $0.1 . A$ & & & & \\
$\mathrm{q}^{2}$ & 0.761 & 0.798 & 0.705 & 0.777 \\
$\mathrm{r}^{2}$ & 0.869 & 0.919 & 0.870 & 0.891 \\
number of comp. & 5 & 5 & 6 & 7 \\
\hline & & & &
\end{tabular}

Table 5. Resisulals for CoMFA and CoMSLA

\begin{tabular}{|c|c|c|c|c|c|}
\hline & Activity & COMFA & $\begin{array}{l}\text { CoMFA } \\
\text { residual }\end{array}$ & COMSLA & $\begin{array}{c}\text { CoMSLA } \\
\text { residual }\end{array}$ \\
\hline S1 & 8.62 & 7.77 & 0.85 & 7.77 & 0.85 \\
\hline S2 & 8.61 & 7.62 & 0.99 & 7.82 & 0.79 \\
\hline S3 & 6.41 & 7.71 & -1.30 & 7.82 & -1.41 \\
\hline S4 & 6.37 & 5.18 & 1.19 & 4.64 & 1.73 \\
\hline$\$ 5$ & 6.04 & 5.88 & 0.16 & 5.00 & 1.04 \\
\hline$\$ 6$ & 1.87 & 1.37 & 0.50 & 2.06 & -0.19 \\
\hline$\$ 7$ & 1.71 & 1.44 & 0.28 & 2.08 & -0.37 \\
\hline$\$ 8$ & 1.35 & 0.91 & 0.44 & 0.57 & 0.79 \\
\hline \$9 & 0.41 & 0.93 & -0.52 & 1.32 & -0.91 \\
\hline$\$ 10$ & 0.21 & 0.77 & -0.56 & 1.32 & -1.11 \\
\hline$\$ 11$ & -1.61 & -1.12 & -0.49 & -1.44 & -0.17 \\
\hline$\$ 12$ & -3.51 & -3.84 & 0.33 & -3.76 & 0.25 \\
\hline $\mathbf{R} 1$ & 8.65 & 8.39 & 0.26 & 8.19 & 0.46 \\
\hline $\mathbf{R} 2$ & 8.65 & 8.70 & -0.05 & 8.25 & 0.40 \\
\hline $\mathbf{R 3}$ & 5.20 & 4.30 & 0.90 & 4.81 & 0.39 \\
\hline R4 & 4.86 & 4.49 & 0.37 & 4.81 & 0.05 \\
\hline R5 & 4.54 & 4.54 & 0.00 & 4.85 & -0.31 \\
\hline R6 & 2.11 & 2.76 & -0.65 & 2.35 & -0.24 \\
\hline $\mathbf{R} 7$ & 1.70 & 1.33 & 0.37 & 1.06 & 0.64 \\
\hline R8 & 1.37 & 2.86 & -1.49 & 2.78 & -1.41 \\
\hline $\mathbf{R} 9$ & 1.37 & 2.60 & -1.23 & 2.37 & -1.00 \\
\hline R10 & 0.99 & 2.37 & -1.38 & 2.78 & -1.79 \\
\hline R11 & 0.74 & 1.36 & -0.62 & 1.55 & -0.81 \\
\hline R12 & 0.17 & -0.59 & 0.76 & -1.26 & 1.43 \\
\hline R13 & -0.22 & -0.43 & 0.21 & -1.20 & 0.98 \\
\hline R14 & -0.78 & -2.52 & 1.74 & -1.68 & 0.90 \\
\hline R15 & -0.62 & -0.64 & 0.02 & -1.26 & 0.64 \\
\hline R16 & -1.59 & -2.31 & 0.72 & -2.19 & 0.60 \\
\hline R17 & -2.41 & -0.63 & -1.78 & -0.18 & -2.23 \\
\hline
\end{tabular}

The Models of CoMFA and CoMSIA used here are the best models in Table 2 and 4. 


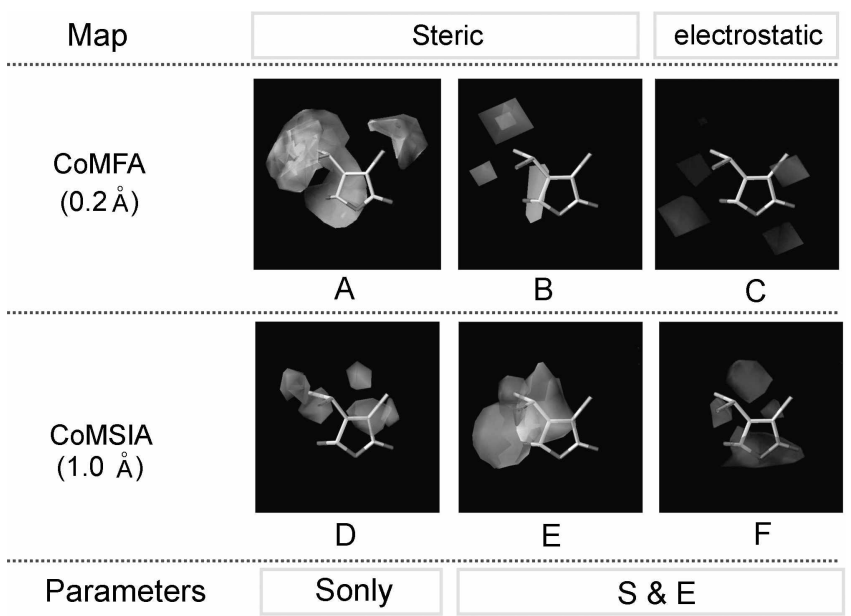

Figure 4. COMl $\curvearrowright$ steric SIDDLV*COLFE contour plots. Stcrically favored arcas (contribution level of $80 \%$ ) are represented by green polyhedra. Sterically dislavored areas (contribution level of $30 \%$ ) are represented by yellow polyhedra (A. B. D. E). Positive charged favored areas (contribution level of $80 \%$ ) are represented by blue ployhedra. Negatively charged favored areas (contribution level of $30 \%$ ) are represented by red polyhedra (C. F). The molecule shown in the maps is $\mathrm{MX}$.

\section{References}

1. Moudgall, C. .: Ljpscomb. J. C.: Bruce. R. W. Toxicology 2000. 1+7. 109-131.

2. (a) Junhe. L.: Huixian. Z.: Chengyong. Y.: Zirui. Y.: Jingi. Z. Wat. Res. 2002. 36. 970-974. (b) Mcicr. I. R.: Blazak. W. F.: Knohl. R. B. Envion. Mol Hat 1987, 10, 411-424. (c) Halonen, I, Tarhanen. I.: Ollikaimen. S.: Ruokojarvi. P.: Tuppurainen. K.: Ruuskanen, J. Chemosphere 1994. 28. 2129-21.38.

3. Maron. D. M.: Ames. B. N. Hat. Res. 1983. /13. 173-215.

4. (a) Tikkanen. L.: Kronberg. L. Hut. Res. 1990. 24t). 109-116. (b) Kronberg. L.: Franzen. R. Frviron. Sci. Techmol. 1993. 27. 18111818. (c) Matsumura, II.: Watanabe. M.: Matsumoto. K.: Ohtel T. J. Tox. Emirom. Healh 1994. 43. 65-72. (d) Jal onde. R. I.: Xie. S.: Chamulitrat. W: Mason. R. P. Chem Res. Toxicol 1994, 7. 482-486. (1) Munter. T.: Curieux. F. L.: Sjoholm. R.: Kronberg. L. (hem. Res. Foricot 1998. /1. 226-233.

5. Miettinen. I.: Martikinen. P.: Vartiainen. T.: Lotjonen. S. Chenosphere 1993, 27, 1707-1718.
6. (a) Munter. T.: Curieux, F. 1.: Sjoholm. R.: Kronberg. I. Chem Res. Toxicol 1999. 12. 40-52. (h) Munter, T. Curieux, I: I..: Sjoholm. R.: Kronberg. L. Chen. Res. Toxicol. 1998. 1/. 226-233.

7. Meier. J. R.: Monarca S.: Patlerson. K. S.: Villarini. M.: Daniel. F.

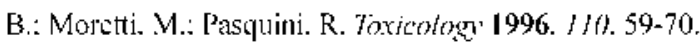

8. Marsteinstredet. U.: Wiger. R.: Brunborg. Ci.: Homgslo. I. K.: I Holme. J. A. Chenico-Biological huterettions 1997. 106.89-107.

9. (a) Mowry. D. I. J. Am. Chem. Soc. 1950, 72, 2535-2537. (b) Nawrocki. I.: Andrzejewski. P.: Zelen. H.: Wasowicz. E. Hot. Res. 2001. 35. 1891-1896

10. (a) Marsteinstredet. U.: Brunborg. G.: Bjoras. M.: Sodcrlund. E.:

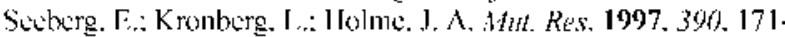
178. (b) Tikkanen. I., Kronbere. 1., Hat. Res. 1990. 2f0. 109-116.

11. (a) Kronberg. I.. Iranzen, R. Emiron. Sci. Tectwol. 1993, 27, 1811-1818. (h) Fran<en. R.: Golo. S.: 'lànabe. K.: Morila M. Wht. Res. 1998. $417.31-37$. (c) Ishiguro. Y.: LaLonde. I.: Dence. C. W. Fwiron. Tor (hem. 1987. 6. 935-946. (d) Ishiguro. Y.: Santodonato J.: Neal. . W. W. Enwion. Hol. Hutagenesis 1988. //. 225-234, (c) 1.aL conde. R. T.: Bu, I.: I lenwood. A.: Fiumano, J: Thang. L. Chem. Res. Toxicol. 1997, /0, 1427-1436. (f) I.al onde. R. T.: Cook. (j. l': Perakyla. H.: Bu. L. Chem Res. Toxicol. 199I. 4. 540-545. (g) LaLonde. R. T.: Xie. S. Chem. Res. Toxicol. 1992. 5. 618-624. (h) Kronberg. L.: Christman. R. F. Sci. Total Environ. 1989. 81. 219-230. (i) Kronberg. I.: Christman. R. F.: Singh. R.: Ball. I. M. Enirom. Sci. Technol. 1991. 25. 99-104. (j) I al onde. R. I.: Xie. S.: 13แ. I. Emiron. Wol. Wh 1993. 22, 181-187. (k) LaLonde. R. I.: Cook. (j. P.: I'eraky la. H.: Dence. C. W. Chen. Res. Toxicol. 1991. 4. 35-40. (1) Meier. I. R.: Knohl. R. B.: Colemant. W. E.: Ringhand. H. P.: Munch. J. W.: Kaylor. W. H.: Stweicher. R. P.: Koptler. F. C. Hut. Res. 1987. $/ 89.363-373$, (m) I al onde. R. T.: I Le. II, R, Chem. Res. Foricol 1994. 7. 779-783. (n) Lal onde, R. I.: Cook. (i. P.: Perakyla II.: Dence. (. W. Babish. J. G. Emiron. Hol Httt. 1991. 17. 40-48.

12. (a) Cho. S. J. Bull. Korean (hem. Soc 2002. 23.929-930. (b) Cho. S. J. Bull. Koreeth (hem. Sod. 2003. 2f. 731-732. (c) Tuppurainen. K.: I otjonen, $S . \therefore$ I atatikainen. R.; Varitiainen. T. Mut. Res. 1992 $181-188$.

13. Kronberg. I: Christman. R. F. Sci. Total Emwiron. 1989. 81 , 219

14. l'oso. A.: luppurainen. K.: Gynther. J. J. Wol. Strot (THE)(XHEM) 1994. 36). 255-260.

15. Cramer, R. D.: Petterson, D. F.: Bunce, I. D. . A tm. Chem. Soc. 1988. $110.5959-5967$.

16. Klebe. (i.: Abraham. (1. J. Comput.-Aided Wol. Design 1999. /3. $1-10$.

17. The LUMO energy levels were found to describe the mulagenicity well in the previous study:

18. QSAR and Advanced CoMFA manual. 